\title{
An update on the use of degarelix in the treatment of advanced hormone-dependent prostate cancer
}

This article was published in the following Dove Press journal:

Onco Targets and Therapy

12 April 2013

Number of times this article has been viewed

Ferenc G Rick'

Norman L Block ${ }^{1-3}$

Andrew V Schally ${ }^{1-3}$

'Endocrine, Polypeptide, and Cancer Institute, Veterans Affairs Medical

Center and South Florida Veterans

Affairs Foundation for Research and

Education, ${ }^{2}$ Department of Pathology, University of Miami, Miller School of

Medicine, ${ }^{3}$ Divisions of Hematology/

Oncology and Endocrinology,

Department of Medicine, University of Miami, Miller School of Medicine, Miami, Florida, USA
Correspondence: Ferenc G Rick Veterans Affairs Medical Center and South Florida Veterans Affairs Foundation for Research and Education, I20I NW I6th St, Research (I5I), Room 2AI03C Miami, FL 33125, USA

Tel + I 3055753477

Fax + I 3055753 I 26

Email ferencrick@gmail.com
Abstract: Androgen deprivation therapy remains the mainstay of medical treatment for advanced prostate cancer. Commonly, this is achieved with medical androgen deprivation rather than surgical intervention as the permanence and psychological effects of the latter are unacceptable for most patients. Degarelix is a third generation antagonist of luteinizing hormone-releasing hormone (LHRH, also termed gonadotropin-releasing hormone) for the first-line treatment of androgen-dependent advanced prostate cancer. Degarelix acts directly on the pituitary receptors for LHRH, blocking the action of endogenous LHRH. The use of degarelix eliminates the initial undesirable surge in gonadotropin and testosterone levels, which is produced by agonists of LHRH. Degarelix is the most comprehensively studied and widely available LHRH antagonist worldwide. Clinical trials have demonstrated that degarelix has a long-term efficacy similar to the LHRH agonist leuprolide in achieving testosterone suppression in patients with prostate cancer. Degarelix, however, produces a faster suppression of testosterone and prostate-specific antigen (PSA), with no testosterone surges or microsurges, and thus prevents the risk of clinical flare in advanced disease. Recent clinical trials demonstrated that treatment with degarelix results in improved disease control when compared with an LHRH agonist in terms of superior PSA progression-free survival, suggesting that degarelix likely delays progression to castration-resistant disease and has a more significant impact on bone serum alkaline phosphatase and follicle-stimulating hormone. Degarelix is usually well tolerated, with limited toxicity and no evidence of systemic allergic reactions in clinical studies. Degarelix thus represents an important addition to the hormonal armamentarium for therapy of advanced androgen-dependent prostate cancer.

Keywords: degarelix, GnRH, LHRH, metastatic prostate cancer, androgen-dependent prostate cancer, hormonal therapy

\section{Introduction}

The American Cancer Society estimated that there were 241,740 new cases of prostate cancer (PCa) in the United States of America in 2012, accounting for $28.5 \%$ of all cancers in men, and 28,170 deaths. ${ }^{1}$ In addition to morbidity and mortality, the socioeconomic burden and the impact of $\mathrm{PCa}$ on quality of life are significant. ${ }^{2}$ The first milestone for the treatment of PCa was in 1941, when Huggins and Hodges reported that the growth of PCa cells requires the androgen, testosterone. ${ }^{3}$ This discovery led to the use of orchiectomy or estrogens as the prevalent methods of androgen deprivation therapy (ADT) for patients with advanced PCa and remained so until the 1970s. ${ }^{4}$

The next major breakthrough in ADT belongs to Andrew Schally and associates, who first isolated and described the structure of the hypothalamic neurohormone, 
luteinizing hormone-releasing hormone (LHRH or gonadotropin-releasing hormone) in $1971 .^{5}$ The Schally group was also the first to show that both natural and synthetic LHRH released luteinizing hormone (LH) and follicle-stimulating hormone (FSH) in humans. ${ }^{6}$ Over the past 40 years, more than 3000 agonistic analogs of LHRH have been synthesized. Of these analogs, the most important are triptorelin, leuprolide, buserelin, nafarelin, and goserelin, which are 50-100 times more potent than LHRH itself. ${ }^{7}$ Endocrine therapy for PCa, based on such agonistic analogs of LHRH, was also developed by the Schally laboratory. ${ }^{8,9}$ Schally and colleagues found that long-term administration of LHRH agonists downregulates pituitary receptors for LHRH, which results in substantially decreased levels of $\mathrm{LH}, \mathrm{FSH}$, and testosterone, providing palliation for patients with advanced $\mathrm{PCa} .{ }^{8}{ }^{8}$ Agonists of $\mathrm{LHRH}$ were found to be safer and equally effective as estrogen. ${ }^{10}$ This groundbreaking work by Schally and the subsequent development of depot formulations of LHRH agonists laid the foundation for current ADT. ${ }^{4}$

Despite their efficacy, however, LHRH agonists were found to have several disadvantages associated with their mode of action. The initial stimulation of pituitary LHRH receptors, in particular, causes a testosterone surge which delays the achievement of castrate testosterone levels for about 2-4 weeks. ${ }^{11}$ This surge may also lead to an exacerbation of clinical symptoms (flare effects) in advanced disease, including increased bone pain, spinal cord compression, ureteral obstruction, urethral obstruction, and even death. ${ }^{12,13}$ Furthermore, LHRH agonists may also cause testosterone microsurges after each dose administration. ${ }^{14}$

More recently, a new approach to ADT has emerged with the development of antagonists of LHRH. This class of agents exerts a direct and immediate blockade of LHRH pituitary receptors and produces rapid testosterone suppression without an initial surge or subsequent microsurges. ${ }^{15}$ Degarelix, a clinically effective third generation LHRH antagonist, is currently available for therapy of advanced PCa in the US; it is also available in several countries in North and South America, Japan, and most European countries. ${ }^{16}$ This review evaluates the efficacy and safety of the LHRH antagonist, degarelix, and collates recently published additional clinical and experimental data.

\section{Mechanism of action of LHRH (gonadotropin-releasing hormone) antagonists}

Antagonists of LHRH induce chemical castration by a mechanism that is different than that of LHRH agonists. ${ }^{17}$
The agonists, acting on pituitary LHRH receptors, produce an intense initial stimulation of release of LH and FSH and, as a consequence, cause a discernible rise in testosterone. Eventually, agonist-induced overstimulation overcomes the natural pulsatile control of LH release, leading to receptor desensitization or downregulation, which in turn suppresses $\mathrm{LH}$ and FSH secretion and consequently reduces testosterone to castrate levels. ${ }^{18}$ Antagonists of LHRH, in contrast, exert their effect directly, competitively binding to and blocking pituitary LHRH receptors and causing an immediate blockade of $\mathrm{LH}$ and FSH secretion. ${ }^{7}$ This results in immediate testosterone suppression, without any initial stimulation or surge. ${ }^{19}$

Animal studies showed not only that administration of LHRH antagonists suppresses LH and testosterone to castrate levels but also that administration of an LHRH antagonist before an agonist will blunt the expected characteristic LH and testosterone surge induced by the agonist. ${ }^{20,21}$ Furthermore, recent in vivo studies in rats suggest that LHRH antagonists, at doses which do not induce castration levels of testosterone, can shrink experimentally enlarged LHRH-receptor-expressing benign prostatic tissue. This inhibition is possibly due to the direct inhibitory effects of LHRH antagonists exerted through prostatic LHRH receptors directly on the tissue concerned. ${ }^{22-24}$ Beneficial effects of antagonists of the hypothalamic neurohormones, LHRH and growth hormone-releasing hormone, on experimental models of benign prostatic hyperplasia and $\mathrm{PCa}$ have been recently reported..$^{25-29}$

\section{Development of LHRH antagonists}

Cetrorelix was the first LHRH antagonist tested clinically in patients with PCa and was shown to induce clinical improvement. ${ }^{30,31}$ Abarelix, the first antagonist available clinically for treatment of PCa, displayed a safety profile comparable to that of the LHRH agonist, leuprolide, with or without the antiandrogen, bicalutamide. ${ }^{32}$ However, immediate-onset systemic allergic reactions (1.1\%) were a major concern with abarelix. ${ }^{16}$ This reaction was related to histamine release. The manufacturer withdrew abarelix from the US market for related commercial reasons. It is currently available in Germany and its launch in other European countries is underway. ${ }^{16}$

The third generation LHRH antagonist, degarelix, was synthetically modified with a view toward reducing this histamine-releasing activity. Degarelix showed only very weak histamine-releasing properties and the lowest capacity for histamine release among the antagonists of LHRH, 
including cetrorelix, abarelix, and ganirelix, when tested in an animal study ${ }^{33}$ and a human skin model. ${ }^{34}$ Additionally, no systemic anaphylactic reactions occurred during the clinical development of degarelix in patients with $\mathrm{PCa} .{ }^{35-37}$ Degarelix is the only LHRH antagonist with this low risk of histamine release currently on the market and available for clinical use in advanced PCa. ${ }^{16}$ Degarelix forms a physicochemical complex after subcutaneous injection. The drug is released in two phases into the bloodstream: ${ }^{38}$ a short, initial, prompt release phase followed by a slow-release phase in which serum levels display a half-life of several weeks. ${ }^{39}$ Data from a Phase III study demonstrated that with a single dose of $240 \mathrm{mg}$ of degarelix, the maximum plasma level $\left(\mathrm{C}_{\text {max }}\right)$ was $66 \mathrm{ng} / \mathrm{mL}$, the area under the concentration-time curve (Day 0-28) was $635 \mathrm{ng}$ per day per $\mathrm{mL}$ and the mean time to $\mathrm{C}_{\text {max }}$ was 40 hours. ${ }^{38}$ Median terminal half-lives for the starting and maintenance doses were about 43 days and 28 days, respectively. The extended half-life after subcutaneous injection of degarelix is thought to be a consequence of a very slow release of the drug from the complex that is formed at the injection site. ${ }^{38}$ In elderly patients or in patients with mild or moderate renal or hepatic impairment, adjustment of dose is not needed. Due to the limited amount of data on patients with severe renal or hepatic dysfunction, caution is warranted in these groups. ${ }^{38}$

\section{Preclinical studies}

Early experimental studies demonstrated that subcutaneous administration of degarelix produced a rapid, reversible, and dose-dependent suppression of the pituitary-gonadal axis, as indicated by a reduction in $\mathrm{LH}$ and testosterone in rat and rhesus monkey preclinical models. ${ }^{33}$ This subcutaneous administration of degarelix leads to the formation of a gel depot-like complex that facilitates sustained drug release, and is reflected in the prolonged LH and testosterone suppression associated with degarelix; which, in comparative studies, displayed a longer duration of action than other LHRH antagonists (abarelix, cetrorelix, ganirelix, and azaline B). ${ }^{40,41}$ Early LHRH antagonists caused histamine release from mast cells, ${ }^{41}$ which resulted in clinically problematic systemic or local anaphylactoid reactions. ${ }^{33}$ Abarelix was associated with a risk of systemic allergic reactions. ${ }^{42}$ In an animal study, degarelix had the lowest activity for histamine release among the LHRH antagonists tested. ${ }^{33}$ An ex vivo human skin model revealed similar findings: degarelix displays the lowest propensity for histamine release when compared to ganirelix, abarelix, and cetrorelix. ${ }^{34}$

Guyader et al recently reported that continuous administration of degarelix inhibited the growth of the high-grade, hormone-dependent human PCa xenograft, PAC120, in nude mice, but $40 \%$ of tumors recurred. ${ }^{43}$ Intermittent androgen deprivation with degarelix or complete blockade using a combination of degarelix monthly and antiandrogens, inhibited tumor growth, but increased the risk of recurrence as compared to continuous castration. The combination of degarelix with the human epidermal growth factor receptor 2 (HER2)/neu inhibitor, trastuzumab, decreased recurrence risk and the combination of degarelix with an mTOR inhibitor (everolimus) prevented recurrence. ${ }^{43}$

\section{Phase II studies}

The efficacy and safety of degarelix was assessed in three randomized, 1-year dose-finding Phase II clinical trials in Europe/ South Africa, ${ }^{35}$ North America, ${ }^{36}$ and $\operatorname{Japan}^{37}$ (Table 1). All three trials were open-label, randomized, parallel-group studies including adult men with histologically confirmed $\mathrm{PCa}$ (all stages), for whom hormonal treatment was indicated.

In the European study, 189 patients were randomized to one of six degarelix treatment groups: starter doses of either 200 or $240 \mathrm{mg}$ followed by monthly maintenance doses of 80,120 , or $160 \mathrm{mg}$, all given via subcutaneous injection. ${ }^{35}$ The patients (median age: 72 years) had median baseline levels of testosterone and prostate-specific antigen (PSA) of $4.13 \mathrm{ng} / \mathrm{mL}$ and $27.6 \mathrm{ng} / \mathrm{mL}$, respectively. Disease stage was localized in $22 \%$, locally advanced in $32 \%$, metastatic in $19 \%$, and not classifiable in $27 \%$ of the patients.

In the North American trial, 127 patients were randomized to one of two degarelix treatment groups: starter dose of $200 \mathrm{mg}$ followed by monthly maintenance doses of either 60 or $80 \mathrm{mg}$, once again all given by subcutaneous injection. ${ }^{36}$ The patients (median age: 76 years) had median baseline levels of testosterone and PSA of $4.13 \mathrm{ng} / \mathrm{mL}$ and $13.4 \mathrm{ng} / \mathrm{mL}$, respectively. Disease stage was localized in $43 \%$, locally advanced in $11 \%$, metastatic in $19 \%$, and not classifiable in $28 \%$ of the patients.

In the Japanese study, 273 patients were treated with an initial subcutaneous dose of degarelix of $240 \mathrm{mg}$ followed by monthly maintenance doses of either 80 or $160 \mathrm{mg} .{ }^{37}$ The patients (median age: 74 years) had median baseline levels of testosterone and PSA of $4.41 \mathrm{ng} / \mathrm{mL}$ and $22.4 \mathrm{ng} / \mathrm{mL}$, respectively. Disease stage was localized in $46 \%$, locally advanced in $30 \%$, metastatic in $23 \%$, and not classifiable in $\leq 1 \%$ of the patients.

In all three Phase II trials, degarelix was well-tolerated and degarelix treatment for 1 year was associated with a rapid, profound, and sustained suppression of testosterone to castrate testosterone levels $(\leq 0.5 \mathrm{ng} / \mathrm{mL})$ without an initial 


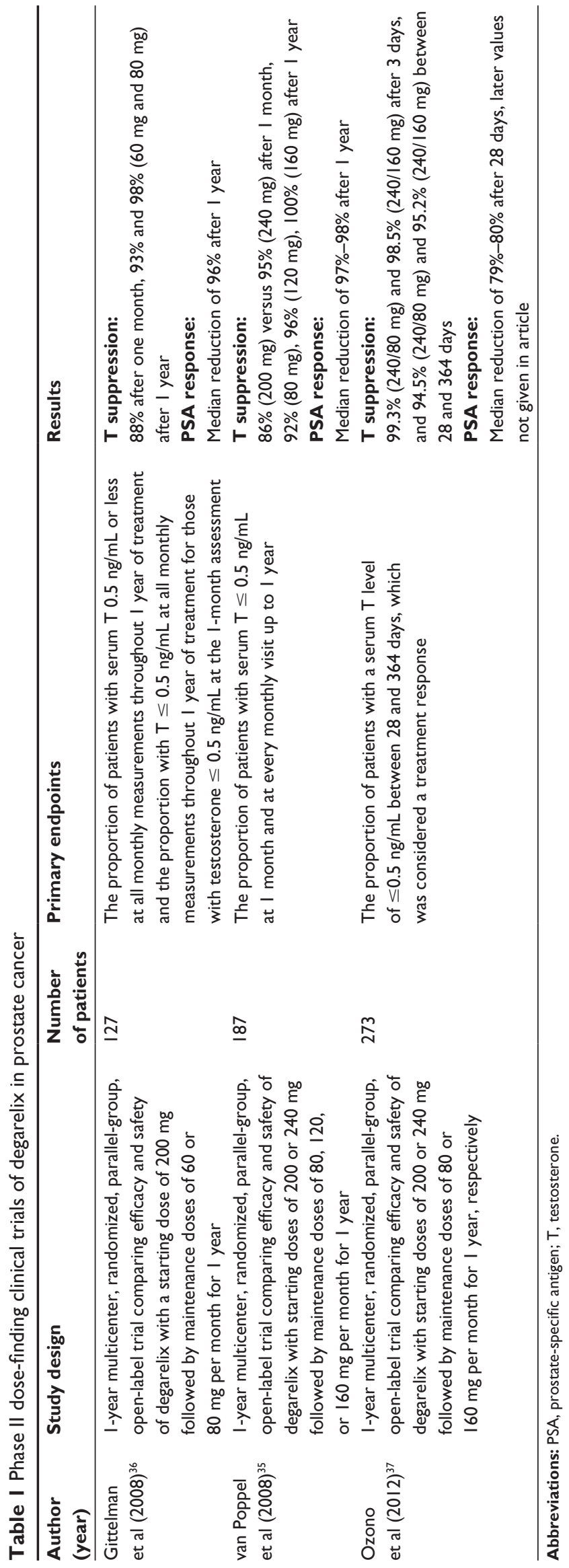

testosterone surge. These trials also showed prompt PSA suppression with degarelix; PSA was maintained at low levels throughout all three studies. In summary, these studies identified the most effective doses of degarelix ( $240 \mathrm{mg}$ loading dose; 80 or $160 \mathrm{mg}$ maintenance dose). These trials also showed that the preferred monthly regimen for patients with $\mathrm{PCa}$ is an initial dose of $240 \mathrm{mg}$ with a monthly maintenance dose of $80 \mathrm{mg}$, taking into account risk and efficacy. ${ }^{41}$

\section{Phase III study}

Based on the dose-finding clinical trials, a 1-year, multicenter, randomized, open label Phase III trial was carried out in North America/Europe. ${ }^{44}$ The study consisted of 610 patients with histologically confirmed PCa for whom ADT was indicated. The patients were randomized to compare efficacy and safety of degarelix at $240 \mathrm{mg}$ for 1 month followed by monthly maintenance doses of $80 \mathrm{mg}$ $(240 / 80 \mathrm{mg})(\mathrm{n}=207)$ or $160 \mathrm{mg}(240 / 160 \mathrm{mg})(\mathrm{n}=202)$ as compared to leuprolide at $7.5 \mathrm{mg}(\mathrm{n}=201)$ monthly. In the leuprolide group, the antiandrogen, bicalutamide, could also be given for flare protection at the investigator's discretion. ${ }^{45}$ The patients (median age: 73 years) had median baseline testosterone and PSA levels of $3.93 \mathrm{ng} / \mathrm{mL}$ and $19.0 \mathrm{ng} / \mathrm{mL}$, respectively. Disease stage was localized in $31 \%$, locally advanced in $29 \%$, metastatic in $20 \%$, and not classifiable in $19 \%$ of the patients.

\section{Efficacy data}

The primary analyses of data from the Phase III clinical trial showed that both degarelix doses were statistically noninferior to leuprolide for the primary endpoint (testosterone response: serum testosterone $\leq 0.5 \mathrm{ng} / \mathrm{mL}$ at all monthly measurements between days 28 and 364 ; Table 2) ${ }^{44}$ At day 3 , testosterone levels $\leq 0.5 \mathrm{ng} / \mathrm{mL}$ were achieved by $96.1 \%$ and $95.5 \%$ of patients in the degarelix $240 / 160 \mathrm{mg}$ and $240 / 80 \mathrm{mg}$ groups, respectively, compared with $0 \%$ in the leuprolide group; corresponding values at day 14 were $100 \%, 99.5 \%$, and $18.2 \%$, respectively. With leuprolide, median testosterone increased from baseline by $65 \%$ after 3 days, and remained at $>0.5 \mathrm{ng} / \mathrm{mL}$ until day 28 . In addition, testosterone surge (defined as a testosterone increase of $\geq 15 \%$ from baseline on any 2 days during the first 2 weeks of treatment) occurred in $80 \%$ of patients in the leuprolide group versus $0 \%$ in degarelix recipients.

In accord with the testosterone results, PSA suppression was also significantly faster in the degarelix $240 / 80 \mathrm{mg}$ and 240/160 mg arms compared to the leuprolide group: at day 14 (64\% and $65 \%$ versus $18 \%$, respectively) and at day $28(85 \%$ 


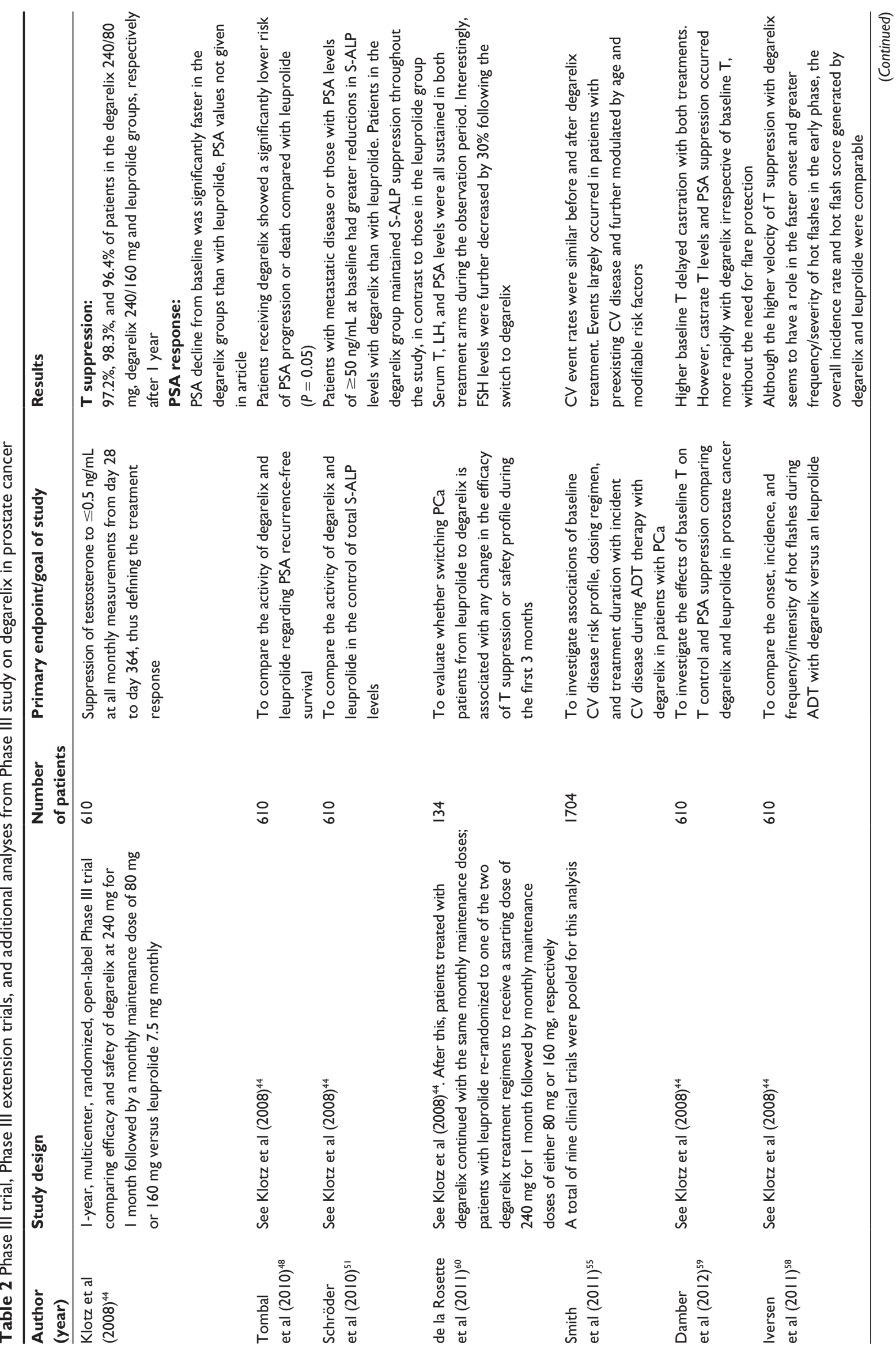




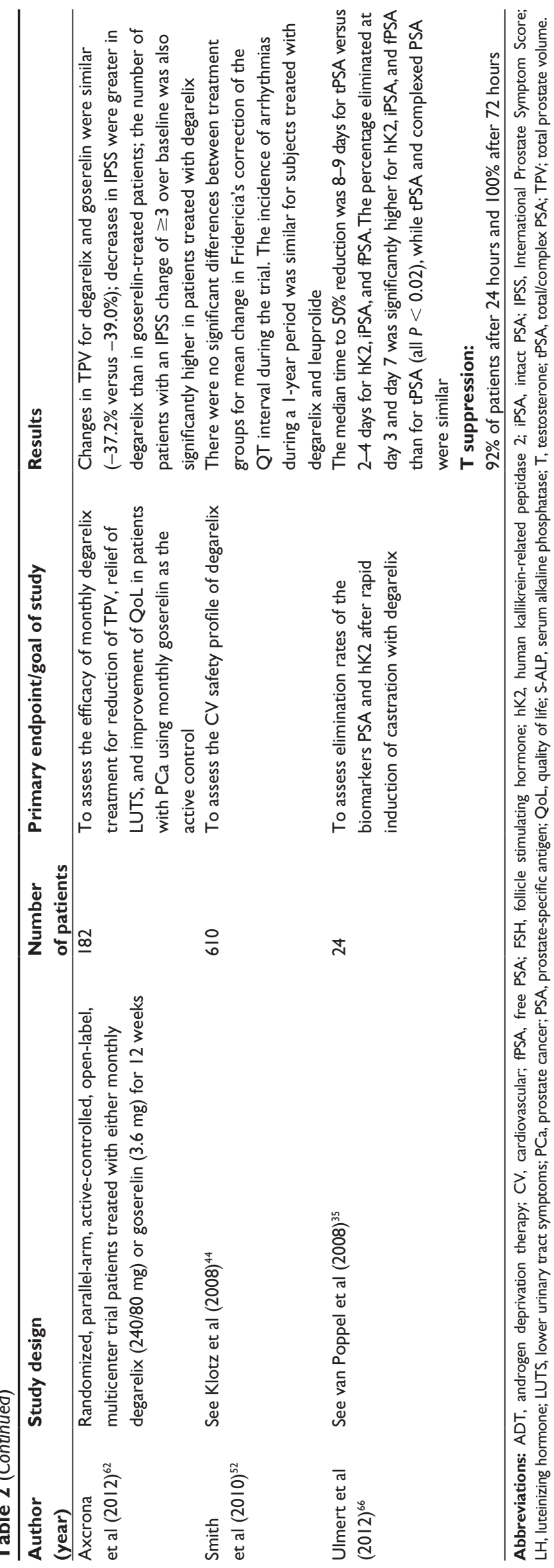

and $83 \%$ versus $68 \%$, respectively). Thus significantly greater suppression was observed as compared with leuprolide. PSA failure (ie, two successive PSA rises of $>50 \%$ versus nadir and PSA $\geq 5 \mathrm{ng} / \mathrm{mL}$ on two consecutive measurements $\geq 2$ weeks apart) was lowest with degarelix 240/80 $\mathrm{mg}$ (the likelihood of PSA failure during the study was $8.9 \%$ with degarelix $240 / 80 \mathrm{mg}, 14.2 \%$ with degarelix $240 / 160 \mathrm{mg}$, and $14.1 \%$ with leuprolide). Treatment with degarelix also resulted in a more prompt suppression of LH and FSH levels. Levels of both of these gonadotropins remained suppressed until the end of the trial. With leuprolide, however, there was an initial increase in LH and FSH, and FSH levels never fell to the same degree as in the degarelix arms.

Based on the safety and efficacy demonstrated in the Phase II and Phase III studies, the degarelix dosage of 240/80 mg was approved by the US Food and Drug Administration in $2008^{46}$ and the European Medicines Agency in $2009^{47}$ for treatment of androgen-dependent advanced PCa.

\section{Phase III study - additional analyses PSA}

The biochemical recurrence rate data in the Phase III trial was reviewed by Tombal et al. ${ }^{48}$ The authors found that, during the first year of treatment, patients treated with 240/80 mg degarelix displayed a markedly lower risk of PSA failure or death (ie, improved PSA progression-free survival [PFS]) compared to leuprolide. After adjusting for baseline PSA and disease stage, the hazard ratio $(0.664 ; 95 \%$ confidence interval: $0.385,1.146$ ) revealed that the risk of PSA failure or death with degarelix was $34 \%$ lower than that with leuprolide. PSA failures occurred mainly in patients with metastatic disease at baseline or PSA levels $>50 \mathrm{ng} / \mathrm{mL}$; no PSA failures occurred in those with baseline PSA levels $\leq 20 \mathrm{ng} / \mathrm{mL}$. In patients with metastatic disease or PSA levels $>20 \mathrm{ng} / \mathrm{mL}$ at baseline, fewer PSA failures occurred with degarelix compared with leuprolide. A higher proportion of patients with metastatic disease treated with degarelix achieved PSA levels $<4 \mathrm{ng} / \mathrm{mL}$ over the study period. Hussain et al reported that a PSA of $\leq 4 \mathrm{ng} / \mathrm{mL}$ after 7 months of ADT is a strong predictor of survival in patients with metastatic $\mathrm{PCa}^{4}{ }^{49}$

\section{Serum alkaline phosphatase (S-ALP)}

$\mathrm{S}$-ALP is a recognized independent marker of metastatic bone disease in patients with PCa. ${ }^{45,50}$ In the Phase III clinical trial, baseline levels of S-ALP were high in patients with metastatic $\mathrm{PCa}$ and highest in patients with metastatic disease and hemoglobin levels of $<13 \mathrm{~g} / \mathrm{dL}$, indicative of the presence of skeletal metastases..$^{51}$ In addition, baseline S-ALP levels were 3-4 times 
higher in patients with a baseline PSA $>50 \mathrm{mg} / \mathrm{mL}$ versus $\leq 50 \mathrm{mg} / \mathrm{mL}$. In all patients with metastatic disease, after initial peaks in both groups, S-ALP levels were suppressed below baseline with 240/80 mg degarelix but were maintained near baseline with leuprolide. The persistent elevation in S-ALP seen with leuprolide, which may suggest treatment failure or occasionally exuberant bone healing, was not apparent with degarelix. Patients with a baseline PSA level of $\geq 50 \mathrm{ng} / \mathrm{mL}$ showed a similar pattern of S-ALP response. The decrease in S-ALP was significantly greater with degarelix 240/80 mg versus leuprolide in patients with baseline metastatic disease $(P=0.014)$ and in those with baseline PSA $>50 \mathrm{ng} / \mathrm{mL} .^{51}$

\section{Cardiovascular safety}

Smith et al assessed the cardiovascular safety data from the Phase III trial and found no significant differences between the pooled degarelix groups and leuprolide for mean change in Fridericia's corrected QT interval. ${ }^{52}$ Fridericia described QT interval variability due to cardiac rate. ${ }^{53}$ Markedly abnormal Fridericia's corrected QT values (500 milliseconds or greater) were observed in only a small number of patients $(\leq 1 \%)$ with either treatment. Supraventricular arrhythmias were the most common type of arrhythmias and affected $2 \%$ of patients in the pooled degarelix group and $4 \%$ in the leuprolide group. Other arrhythmias (eg, ventricular arrythmias, bradycardia, AV conduction disturbances, and bundle branch block) occurred in $1 \%$ or less of subjects in each treatment group. This was a cardiologically biased sample as bundle branch block in an aging population would be expected to be higher than that observed in the study of Smith el al. ${ }^{54}$ The most frequent cardiac disorder, ischemic heart disease, occurred in $4 \%$ of patients treated with degarelix and $10 \%$ of those on leuprolide. Among ischemic heart diseases, the most frequent events were chronic myocardial ischemia and myocardial infarction (each observed in $<1 \%$ of degarelix patients and in $2 \%$ of those on leuprolide). Cardiac failure occurred in $<1 \%$ of degarelix patients versus $2 \%$ of leuprolide patients.

Another study examined potential associations of cardiovascular disease (CVD) risk profile, dosing regimen, and treatment duration, with incident CVD during ADT with degarelix in 1704 men who participated in nine different clinical trials. ${ }^{55}$ The proportion of CVD events was similar before and after degarelix treatment in the total population. Multivariate analyses demonstrated that CVD at baseline was the strongest independent predictor of events, followed by older age, alcohol abstinence, and obesity (each $P<0.05$ ). Degarelix dose and treatment schedule were not independently associated with CVD events. ${ }^{55}$

\section{Health-related quality of life}

A recent study using standard short form-12 (SF-12) and European Organization for Research and Treatment of Cancer Quality of Life Questionnaires (EORTC QLQ-C30) at the end of the Phase III study found that the health-related quality of life was similar for patients receiving degarelix 240/80 mg versus leuprolide. ${ }^{56}$ Mean SF-12 scores for the mental component summary and mental health were significantly higher (ie, improved) in patients treated with degarelix compared to leuprolide. Conversely, treatment with leuprolide had a seemingly more favorable impact on insomnia and bodily pain as compared with degarelix. In patients with metastatic disease treated with degarelix, significant improvements occurred in global health status and appetite at 12 months, compared to leuprolide.

\section{5-year phase III extension trial}

Crawford et al investigated the long-term efficacy and safety of degarelix in an ongoing long-term extension of the Phase III trial with a median 27.5-month follow-up. ${ }^{57}$ Those patients who completed the 1-year Phase III trial continued on the same monthly degarelix maintenance dose (160 or $80 \mathrm{mg}$ [ $\mathrm{n}=125 \mathrm{each}])$ or were re-randomized from leuprolide $7.5 \mathrm{mg}$ to degarelix $240 / 80 \mathrm{mg}(\mathrm{n}=69)$ or degarelix $240 / 160 \mathrm{mg}(\mathrm{n}=65)$. The interim analysis revealed that, during the follow-up, testosterone and PSA suppression were similar to those in the 1-year trial in patients who continued on degarelix or switched from leuprolide. The PFS hazard rate was significantly decreased (by $>50 \%$ ) after the switch in the leuprolide/degarelix group while the rate in those who continued on degarelix was consistent with the rate in treatment year 1. A similar change in hazard rate pattern was observed in the group with baseline PSA levels $>20 \mathrm{ng} / \mathrm{mL}$. For patients continuing on degarelix $240 / 80 \mathrm{mg}$, there was no significant change in PSA PFS hazard rates. ${ }^{57}$

\section{Occurrence of hot flashes}

Iversen et al compared the onset, incidence, and frequency/ intensity of hot flashes during ADT by patients treated with degarelix versus the LHRH agonist, leuprolide, using data from the randomized Phase III clinical trial. ${ }^{58}$ The onset of hot flashes was earlier with degarelix compared to leuprolide, and was accompanied by higher median hot flash scores during the first 3 months. Although the higher velocity of testosterone suppression with degarelix seems to have a role in the faster onset and greater frequency/severity of hot flashes in the early phase, there were no significant differences in overall incidence rates and median hot flash scores over the 


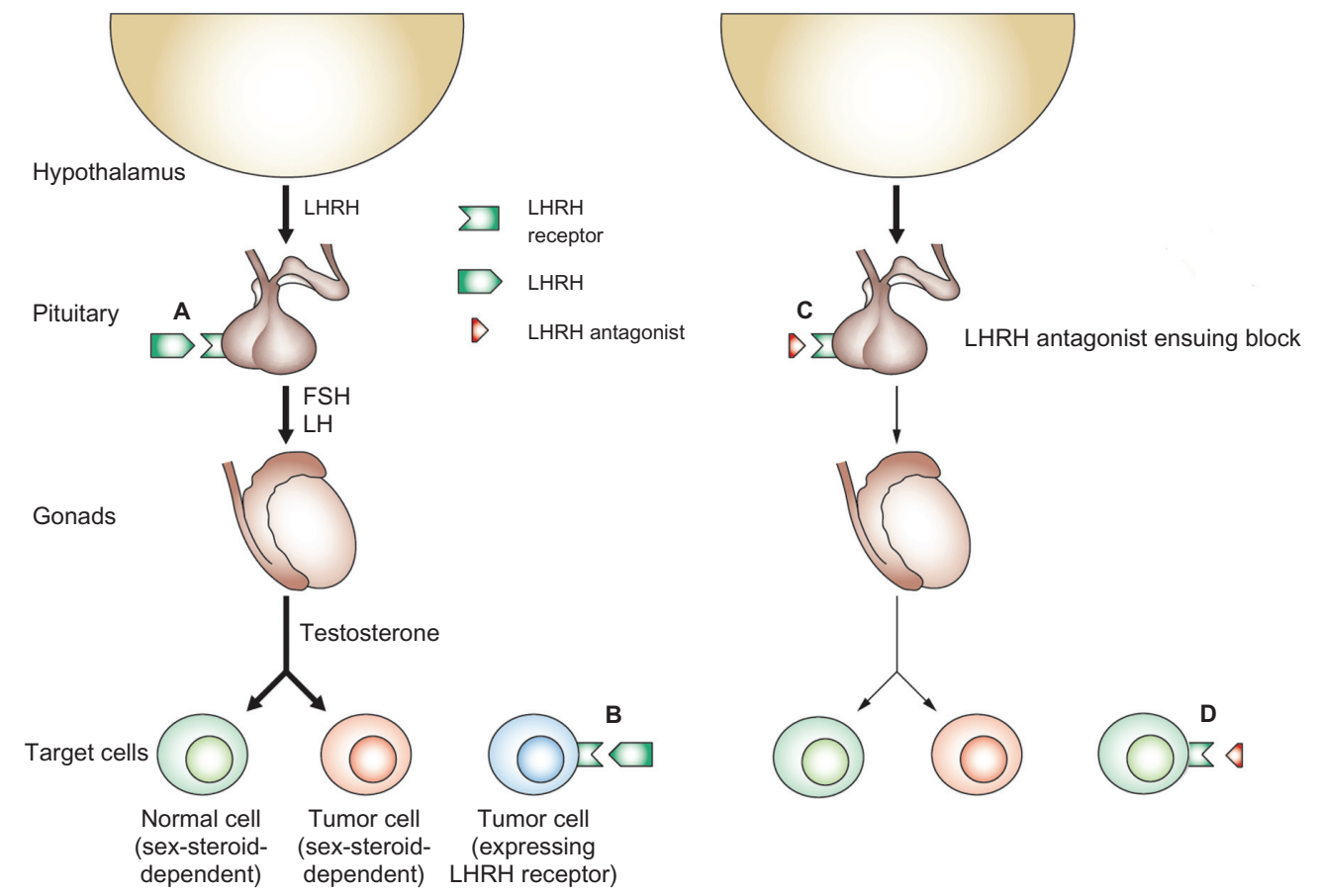

Figure I Mode of action of antagonists of LHRH. (A) LHRH secreted by the hypothalamus binds to its receptor in the pituitary and stimulates the release of LH and FSH. These hormones, in turn, stimulate the release of sex steroids, which can stimulate growth and development of both normal and tumor cells. (B) Some tumors express LHRH receptors and can respond directly to LHRH; cells in these tumors can be sex-steroid-dependent or sex-steroid-independent. (C) LHRH antagonists induce a state of sex steroid deprivation by competitive blockade of pituitary LHRH receptors, whereas LHRH agonists achieve a similar effect by downregulation of the pituitary receptors for $\mathrm{LHRH}$. Consequently, levels of FSH and LH, and subsequently levels of sex steroids, are lowered. The decrease in the levels of sex steroids inhibits the proliferation of both benign and malignant sex-steroid-dependent cells. (D) In tumors that express LHRH receptors, both antagonists and agonists of LHRH may exert direct effects mediated by these LHRH receptors.

Modified from Engel JB and Schally AV with permission. ${ }^{18}$ Copyright 2013 Nature Publishing Group.

Abbreviations: $\mathrm{FSH}$, follicle-stimulating hormone; $\mathrm{LH}$, luteinizing hormone; $\mathrm{LHRH}$, luteinizing hormone-releasing hormone.

entire 12 months. The authors found by multivariate analysis that body weight and heart rate at baseline were independent predictors of hot flashes and suggested that weight control may help to minimize the incidence of hot flashes. ${ }^{58}$

\section{Baseline testosterone}

The effects of baseline testosterone and PSA suppression using data from the Phase III trial were reported by Damber et al. ${ }^{57}$ Data for the groups receiving degarelix $240 / 80 \mathrm{mg}$ (the approved dose) and leuprolide $7.5 \mathrm{mg}$ were compared. Although elevated baseline testosterone delayed castration with both treatments, castrate testosterone levels and suppression of PSA occurred more rapidly with degarelix regardless of baseline testosterone levels, thus implying no need for flare protection. In the case of leuprolide, the magnitude of the testosterone surge and microsurges increased with higher levels of baseline testosterone. There was no correlation between baseline testosterone and initial PSA decrease in either treatment group, although PSA suppression tended to be faster with degarelix and slower with leuprolide in the high baseline testosterone subgroup. ${ }^{59}$

\section{Switching from the agonist leuprolide to the antagonist degarelix}

To evaluate whether switching PCa patients from leuprolide to degarelix is associated with any change in the efficacy of testosterone suppression or safety profile during the first 3 months, patients with histologically confirmed $\mathrm{PCa}$ $(\mathrm{n}=134)$ who had completed 1 year of treatment with leuprolide $7.5 \mathrm{mg}$ monthly were crossed over to degarelix. ${ }^{57,60}$ These patients were re-randomized for the extension trial to receive a starting dose of $240 \mathrm{mg}$ of degarelix followed by monthly maintenance doses of either $80 \mathrm{mg}(\mathrm{n}=69)$ or $160 \mathrm{mg}(\mathrm{n}=65)$. Efficacy was measured by the biomarkers serum testosterone, LH, and PSA; low levels of which were all sustained in both treatment arms during the 3 months of observation. Interestingly, FSH levels were further reduced by $30 \%$ following the switch to degarelix. Other than reactions at injection sites, the overall prevalence and pattern of adverse events (AEs) during the first 3 months after the switch was comparable to that during the last 3 months of leuprolide treatment in the main trial. Five (4\%) patients 
were discontinued due to treatment-related AEs, including injection site pain $(n=3)$ and fatigue $(n=2)$. These data suggest that patients with PCa can be safely switched from leuprolide to degarelix treatment with sustained efficacy as measured by biochemical markers. ${ }^{60}$

A small study by Raddin et al reported two patients with advanced PCa who failed to achieve castrate levels of testosterone while on the LHRH agonist, leuprolide, but subsequently responded to the LHRH antagonist, degarelix. ${ }^{61}$ The first patient was a 63-year-old man with metastatic PCa, who received leuprolide. Initially, he responded with marked PSA suppression $(0.6 \mathrm{ng} / \mathrm{mL})$. However, after 15 months of therapy, his PSA rose to $18.3 \mathrm{ng} / \mathrm{mL}$ and his testosterone to $208 \mathrm{ng} / \mathrm{dL}$. He was switched to degarelix; a month later his testosterone was effectively suppressed to $16 \mathrm{ng} / \mathrm{dL}$. The second patient was a 41-year-old man with metastatic PCa. He was started on leuprolide, but after 3 months, was found to have a rising PSA and a testosterone of $96 \mathrm{ng} / \mathrm{dL}$. A month after switching to degarelix, his testosterone was $18 \mathrm{ng} / \mathrm{dL}$ and his PSA diminished concordantly. With continued monthly injections of degarelix, his testosterone levels remained at $<20 \mathrm{ng} / \mathrm{dL}$ over 7 months of follow-up. ${ }^{61}$

\section{Volume reduction, lower urinary tract symptoms (LUTS) relief, and quality of life}

In patients $(\mathrm{n}=182)$ with $\mathrm{PCa}$, a randomized, parallel-arm, active-controlled, open-label, multicenter trial assessed the efficacy of monthly degarelix treatment for the reduction of total prostate volume (TPV), relief of LUTS, and improvement of quality of life compared to monthly treatment of the LHRH agonist, goserelin, as the active control. ${ }^{62}$ Subjects received either monthly degarelix $(240 / 80 \mathrm{mg})$ or goserelin $(3.6 \mathrm{mg})$ for 12 weeks. For flare protection, goserelin-treated patients also received daily the antiandrogen, bicalutamide (50 mg), during the initial 28 days of therapy. After 12 weeks, reductions of TPV for degarelix and goserelin were similar (37.2\% versus $39.0 \%$ ) and met the predefined noninferiority criteria. Drops in the International Prostate Symptom Score (IPSS) were greater in degarelix-treated patients than in goserelin-treated patients; differences were statistically significant in those patients with a baseline IPSS $>13$ $(-6.7 \pm 1.8$ versus $-4.0 \pm 1.0)$. The number of patients with an IPSS change of $\geq 3$ over baseline was also markedly higher in degarelix-treated patients $(61.0 \%$ versus $44.3 \%)$. Both treatment regimens were safe and well-tolerated. Although prostate volume reduction was equal in the two treatment regimes, degarelix had significantly more pronounced effects on LUTS. The authors suggested that the observed differences could be due to the difference between the action of an agonist and that of an antagonist on extrapituitary LHRH receptors in the prostate and/or the urinary bladder. ${ }^{62}$ Another possibility is that the goserelin flare caused an initial increase in TPV and LUTS and was not yet equalized at 12 weeks.

In a similar, smaller study (degarelix, $\mathrm{n}=27$; goserelin and bicalutamide $[\mathrm{G}+\mathrm{B}], \mathrm{n}=13$ ), significantly more degarelix patients had improved quality of life (IPSS question) at week 12 than patients receiving $\mathrm{G}+\mathrm{B}$ (85\% versus $46 \%) .{ }^{64}$ Mean prostate size reductions at week 12 were $42 \%$ and $25 \%$ for patients receiving degarelix and $\mathrm{G}+\mathrm{B}$, respectively. In men with predominantly locally advanced $\mathrm{PCa}$ and highly symptomatic LUTS, degarelix was at least noninferior to $\mathrm{G}+\mathrm{B}$ in reducing IPSS at week $12 .{ }^{63}$

\section{Suppression of FSH}

A high expression of FSH receptors on the surface of blood vessels has been demonstrated in various tumors, including $\mathrm{PCa}^{64}$ Hormone-refractory (androgen-independent) $\mathrm{PCa}$ cells express FSH and biologically active FSH receptors. ${ }^{65}$ Ben-Josef et al ${ }^{65}$ suggested that $\mathrm{FSH}$ receptors and their ligands may play a role in the regulation of the growth of hormone-refractory $\mathrm{PCa}$. In the Phase III trial, treatment with degarelix resulted in a more rapid suppression of FSH levels than leuprolide ${ }^{44}$ and FSH remained suppressed until the end of the trial. In addition, there was an initial increase in LH and FSH with leuprolide, and FSH levels never fell to the same degree as in the degarelix arms. Furthermore, in an extension trial where patients were switched from leuprolide to degarelix, FSH levels were further reduced by $30 \%$ following the switch to degarelix. ${ }^{60}$ It has been hypothesized that FSH receptors could be involved in the induction of vascular endothelial growth factor (VEGF) and VEGF-2 signaling and therefore the promotion of angiogenesis. Although this hypothesis is unproven, the inhibition of FSH levels by degarelix might be beneficial for the inhibition of tumor growth.

\section{Conclusion}

As orchiectomy is unacceptable to many PCa patients, medical castration by agonists and antagonists of LHRH receptors now provides the mainstay of ADT for advanced PCa. Multiple clinical studies have demonstrated that degarelix, a third generation LHRH antagonist, is an effective and well-tolerated treatment for advanced PCa. Degarelix rapidly suppresses 
testosterone and PSA, without the initial testosterone surge or microsurges associated with LHRH agonists. Degarelix also demonstrates long-term efficacy, maintaining effective suppression of testosterone and PSA for $>3$ years. Compared to agonists of LHRH, treatment with degarelix resulted in improved testosterone and PSA control, offering a prolonged delay to progression, an improved FSH profile, and more favorable effects on S-ALP. Degarelix is generally well-tolerated, without systemic allergic reactions; with the exception of reactions at the injection site, most AEs are related to androgen suppression or the underlying condition. ${ }^{41}$

The favorable pharmacologic profile of degarelix implements clinical advantages in the therapy of PCa including: (1) a delay in progression to castration-resistant disease as compared to LHRH agonists, (2) evasion of the negative clinical effects associated with surge-induced flare, (3) a monotherapy approach to ADT that may improve patient compliance and avoids the addition of antiandrogens (and any attendant AEs), (4) the prolongation of control of skeletal metastases compared to LHRH agonists, and (5) possible clinical benefits associated with improved FSH control. ${ }^{41}$

Therefore, degarelix, which is now the most expansively studied and widely available LHRH antagonist, provides an alternative option to agonists of LHRH as a mainstay for the hormonal management of PCa.

\section{Acknowledgments}

Some of the studies on LHRH agonists and antagonists cited in this review were supported by a grant from the American Urological Association (AUA) Foundation Research Scholars Program and the AUA Southeastern Section (to Ferenc G Rick), by the Medical Research Service of the Veterans Affairs Department, Departments of Pathology, and Medicine, Division of Hematology/Oncology of the Miller Medical School, University of Miami and South Florida Veterans Affairs Foundation for Research and Education (all to Andrew V Schally), and by the L Austin Weeks Endowment for Urologic Research (to Norman L Block).

\section{Disclosure}

The authors report no conflicts of interest in this work.

\section{References}

1. Siegel R, Naishadham D, Jemal A. Cancer statistics, 2012. CA Cancer J Clin. 2012;62(1):10-29.

2. Pommerville PJ, de Boer JG. GnRH antagonists in the treatment of advanced prostate cancer. Can J Urol. 2010;17(2):5063-5070.

3. Huggins C, Hodges CV. Studies on prostatic cancer. I. The effect of castration, of estrogen and of androgen injection on serum phosphatases in metastatic carcinoma of the prostate. 1941. J Urol. 2002;168(1):9-12.
4. Sartor O. Androgen deprivation - continuous, intermittent, or none at all? N Engl J Med. 2012;367(10):945-946.

5. Schally AV, Arimura A, Baba Y, et al. Isolation and properties of the FSH and LH-releasing hormone. Biochem Biophys Res Commun. 1971;43(2):393-399.

6. Schally AV, Arimura A, Kastin AJ, et al. Gonadotropin-releasing hormone: one polypeptide regulates secretion of luteinizing and folliclestimulating hormones. Science. 1971;173(4001):1036-1038.

7. Schally AV. Luteinizing hormone-releasing hormone analogues and hormone ablation for prostate cancer: state of the art. BJU Int. 2007; 100 Suppl 2:2-4.

8. Redding TW, Schally AV. Inhibition of prostate tumor growth in two rat models by chronic administration of D-Trp6 analogue of luteinizing hormone-releasing hormone. Proc Natl Acad Sci U S A. 1981;78(10):6509-6512.

9. Tolis G, Ackman D, Stellos A, et al. Tumor growth inhibition in patients with prostatic carcinoma treated with luteinizing hormone-releasing hormone agonists. Proc Natl Acad Sci U S A. 1982;79(5):1658-1662.

10. Leuprolide versus diethylstilbestrol for metastatic prostate cancer. The Leuprolide Study Group. N Engl J Med. 1984;311(20):1281-1286.

11. Schröder F, Crawford ED, Axcrona K, Payne H, Keane TE. Androgen deprivation therapy: past, present and future. BJU Int. 2012;109 Suppl 6: $1-12$.

12. Thompson IM. Flare Associated with LHRH-Agonist Therapy. Rev Urol. 2001;3 Suppl 3:S10-S14.

13. van Poppel H, Nilsson S. Testosterone surge: rationale for gonadotropinreleasing hormone blockers? Urology. 2008;71(6):1001-1006.

14. Van Poppel H, Klotz L. Gonadotropin-releasing hormone: an update review of the antagonists versus agonists. Int $J$ Urol. 2012;19(7):594-601.

15. Persson BE, Kold Olesen T, Jensen JK. Degarelix: a new approach for the treatment of prostate cancer. Neuroendocrinology. 2009;90(3): 235-244.

16. Shore ND, Abrahamsson PA, Anderson J, Crawford ED, Lange P. New considerations for ADT in advanced prostate cancer and the emerging role of GnRH antagonists. Prostate Cancer Prostatic Dis. 2013;16(1):7-15.

17. Boccon-Gibod L, van der Meulen E, Persson BE. An update on the use of gonadotropin-releasing hormone antagonists in prostate cancer. Ther Adv Urol. 2011;3(3):127-140.

18. Engel JB, Schally AV. Drug Insight: clinical use of agonists and antagonists of luteinizing-hormone-releasing hormone. Nat Clin Pract Endocrinol Metab. 2007;3(2):157-167.

19. Stangelberger A, Schally AV, Djavan B. New treatment approaches for prostate cancer based on peptide analogues. Eur Urol. 2008;53(5): 890-900.

20. Pinski J, Yano T, Miller G, Schally AV. Blockade of the LH response induced by the agonist D-Trp-6-LHRH in rats by a highly potent LH-RH antagonist SB-75. Prostate. 1992;20(3):213-224.

21. Sharma OP, Weinbauer GF, Behre HM, Nieschlag E. The gonadotropinreleasing hormone $(\mathrm{GnRH})$ agonist-induced initial rise of bioactive $\mathrm{LH}$ and testosterone can be blunted in a dose-dependent manner by $\mathrm{GnRH}$ antagonist in the non-human primate. Urol Res. 1992;20(5):317-321.

22. Rick FG, Schally AV, Block NL, et al. LHRH antagonist Cetrorelix reduces prostate size and gene expression of proinflammatory cytokines and growth factors in a rat model of benign prostatic hyperplasia. Prostate. 2011;71(7):736-747.

23. Rick FG, Szalontay L, Schally AV, et al. Combining growth hormonereleasing hormone antagonist with luteinizing hormone-releasing hormone antagonist greatly augments benign prostatic hyperplasia shrinkage. J Urol. 2012;187(4):1498-1504.

24. Rick FG, Schally AV, Block NL, Abi-Chaker A, Krishan A, Szalontay L. Mechanisms of synergism between antagonists of growth hormonereleasing hormone and antagonists of luteinizing hormone-releasing hormone in shrinking experimental benign prostatic hyperplasia. Prostate. Epub December 31, 2012. 
25. Heinrich E, Schally AV, Buchholz S, et al. Dose-dependent growth inhibition in vivo of $\mathrm{PC}-3$ prostate cancer with a reduction in tumoral growth factors after therapy with GHRH antagonist MZ-J-7-138. Prostate. 2008;68(16):1763-1772.

26. Rick FG, Saadat SH, Szalontay L, et al. Hormonal manipulation of benign prostatic hyperplasia. Curr Opin Urol. 2013;23(1):17-24.

27. Rick FG, Schally AV, Block NL, et al. Antagonists of growth hormonereleasing hormone (GHRH) reduce prostate size in experimental benign prostatic hyperplasia. Proc Natl Acad Sci U S A. 2011;108(9): 3755-3760.

28. Rick FG, Schally AV, Szalontay L, et al. Antagonists of growth hormone-releasing hormone inhibit growth of androgen-independent prostate cancer through inactivation of ERK and Akt kinases. Proc Natl Acad Sci U S A. 2012;109(5):1655-1660.

29. Stangelberger A, Schally AV, Rick FG, et al. Inhibitory effects of antagonists of growth hormone releasing hormone on experimental prostate cancers are associated with upregulation of wild-type p53 and decrease in p21 and mutant p53 proteins. Prostate. 2012;72(5):555-565.

30. Gonzalez-Barcena D, Vadillo-Buenfil M, Gomez-Orta F, et al. Responses to the antagonistic analog of LH-RH (SB-75, Cetrorelix) in patients with benign prostatic hyperplasia and prostatic cancer. Prostate. 1994;24(2):84-92.

31. Gonzalez-Barcena D, Vadillo-Buenfil M, Cortez-Morales A, et al. Luteinizing hormone-releasing hormone antagonist cetrorelix as primary single therapy in patients with advanced prostatic cancer and paraplegia due to metastatic invasion of spinal cord. Urology. 1995;45(2):275-281.

32. Debruyne F, Bhat G, Garnick MB. Abarelix for injectable suspension: first-in-class gonadotropin-releasing hormone antagonist for prostate cancer. Future Oncol. 2006;2(6):677-696.

33. Broqua P, Riviere PJ, Conn PM, Rivier JE, Aubert ML, Junien JL. Pharmacological profile of a new, potent, and long-acting gonadotropin-releasing hormone antagonist: degarelix. $J$ Pharmacol Exp Ther. 2002;301(1):95-102.

34. Koechling W, Hjortkjaer R, Tankó LB. Degarelix, a novel GnRH antagonist, causes minimal histamine release compared with cetrorelix, abarelix and ganirelix in an ex vivo model of human skin samples. Br J Clin Pharmacol. 2010;70(4):580-587.

35. Van Poppel H, Tombal B, de la Rosette JJ, Persson BE, Jensen JK, Kold Olesen T. Degarelix: a novel gonadotropin-releasing hormone $(\mathrm{GnRH})$ receptor blocker - results from a 1-yr, multicentre, randomised, phase 2 dosage-finding study in the treatment of prostate cancer. Eur Urol. 2008;54(4):805-813.

36. Gittelman M, Pommerville PJ, Persson BE, Jensen JK, Olesen TK; Degarelix Study Group. A 1-year, open label, randomized phase II dose finding study of degarelix for the treatment of prostate cancer in North America. J Urol. 2008;180(5):1986-1992.

37. Ozono S, Ueda T, Hoshi S, et al. The efficacy and safety of degarelix, a GnRH antagonist: a 12-month, multicentre, randomized, maintenance dose-finding phase II study in Japanese patients with prostate cancer. Jpn J Clin Oncol. 2012;42(6):477-484.

38. Frampton JE, Lyseng-Williamson KA. Degarelix. Drugs. 2009;69(14): 1967-1976.

39. Steinberg M. Degarelix: a gonadotropin-releasing hormone antagonist for the management of prostate cancer. Clin Ther. 2009;31 Pt 2: 2312-2331.

40. Princivalle $\mathrm{M}$, Broqua $\mathrm{P}$, White $\mathrm{R}$, et al. Rapid suppression of plasma testosterone levels and tumor growth in the dunning rat model treated with degarelix, a new gonadotropin-releasing hormone antagonist. J Pharmacol Exp Ther. 2007;320(3):1113-1118.

41. Shore ND. Experience with degarelix in the treatment of prostate cancer. Ther Adv Urol. 2013;5(1):11-24.

42. Mongiat-Artus P, Teillac P. Abarelix: the first gonadotrophin-releasing hormone antagonist for the treatment of prostate cancer. Expert Opin Pharmacother. 2004;5(10):2171-2179.

43. Guyader C, Céraline J, Gravier E, et al. Risk of hormone escape in a human prostate cancer model depends on therapy modalities and can be reduced by tyrosine kinase inhibitors. PLoS One. 2012; 7(8):e42252.
44. Klotz L, Boccon-Gibod L, Shore ND, et al. The efficacy and safety of degarelix: a 12-month, comparative, randomized, open-label, parallel-group phase III study in patients with prostate cancer. BJU Int . 2008;102(11):1531-1538.

45. Van Poppel H. Evaluation of degarelix in the management of prostate cancer. Cancer Manag Res. 2010;2:39-52.

46. US Food and Drug Administration. FDA Approves Drug for Patients with Advanced Prostate Cancer; 29 Dec 2008. Available from: http:// www.fda.gov/NewsEvents/Newsroom/PressAnnouncements/2008/ ucm117001.html Accessed March 2013.

47. European Medicines Agency. Assessment Report for Firmagon; 4 Mar 2009. Available from: http://www.emea.europa.eu/docs/en_GB/ document_library/EPAR_Public_assessment_report/human/000986/ WC500023256.pdf Accessed March 2013.

48. Tombal B, Miller K, Boccon-Gibod L, et al. Additional analysis of the secondary end point of biochemical recurrence rate in a phase 3 trial (CS21) comparing degarelix $80 \mathrm{mg}$ versus leuprolide in prostate cancer patients segmented by baseline characteristics. Eur Urol. 2010;57(5):836-842.

49. Hussain M, Tangen CM, Higano C, et al; Southwest Oncology Group Trial 9346 (INT-0162). Absolute prostate-specific antigen value after androgen deprivation is a strong independent predictor of survival in new metastatic prostate cancer: data from Southwest Oncology Group Trial 9346 (INT-0162). J Clin Oncol. 2006;24(24):3984-3990.

50. Sonpavde G, Pond GR, Berry WR, et al. Serum alkaline phosphatase changes predict survival independent of PSA changes in men with castration-resistant prostate cancer and bone metastasis receiving chemotherapy. Urol Oncol. 2012;30(5):607-613.

51. Schröder FH, Tombal B, Miller K, et al. Changes in alkaline phosphatase levels in patients with prostate cancer receiving degarelix or leuprolide: results from a 12 -month, comparative, phase III study. BJU Int. 2010;106(2):182-187.

52. Smith MR, Klotz L, Persson BE, Olesen TK, Wilde AA. Cardiovascular safety of degarelix: results from a 12-month, comparative, randomized, open label, parallel group phase III trial in patients with prostate cancer. J Urol. 2010;184(6):2313-2319.

53. Fridericia LS. The duration of systole in an electrocardiogram in normal humans and in patients with heart disease. 1920. Ann Noninvasive Electrocardiol. 2003;8(4):343-351.

54. Eriksson P, Hansson PO, Eriksson H, Dellborg M. Bundle-branch block in a general male population: the study of men born 1913. Circulation. 1998;98(22):2494-2500.

55. Smith MR, Klotz L, van der Meulen E, Colli E, Tankó LB. Gonadotropin-releasing hormone blockers and cardiovascular disease risk: analysis of prospective clinical trials of degarelix. J Urol. 2011; 186(5):1835-1842.

56. Gittelman M, Brown TM, Holm-Larsen T, et al. Comparison of the impact of degarelix and leuprolide on the health-related quality of life of patients with prostate cancer: results of a 12 -month phase III clinical trial. Uro Today Int J. 2011;4(6):art 81.

57. Crawford ED, Tombal B, Miller K, et al. A phase III extension trial with a 1-arm crossover from leuprolide to degarelix: comparison of gonadotropin-releasing hormone agonist and antagonist effect on prostate cancer. J Urol. 2011;186(3):889-997.

58. Iversen P, Karup C, van der Meulen E, Tankó LB, Huhtaniemi I. Hot flushes in prostatic cancer patients during androgen-deprivation therapy with monthly dose of degarelix or leuprolide. Prostate Cancer Prostatic Dis. 2011;14(2):184-190.

59. Damber JE, Tammela TL, Iversen $P$, et al. The effect of baseline testosterone on the efficacy of degarelix and leuprolide: further insights from a 12-month, comparative, phase III study in prostate cancer patients. Urology. 2012;80(1):174-180.

60. de la Rosette J, Davis R 3rd, Frankel D, Kold Olesen T. Efficacy and safety of androgen deprivation therapy after switching from monthly leuprolide to monthly degarelix in patients with prostate cancer. Int $J$ Clin Pract. 2011;65(5):559-566. 
61. Raddin RS, Walko CM, Whang YE. Response to degarelix after resistance to luteinizing hormone-releasing hormone agonist therapy for metastatic prostate cancer. Anticancer Drugs. 2011;22(3):299-302.

62. Axcrona K, Aaltomaa S, da Silva CM, et al. Androgen deprivation therapy for volume reduction, lower urinary tract symptom relief and quality of life improvement in patients with prostate cancer: degarelix vs goserelin plus bicalutamide. BJU Int. 2012;110(11):1721-1728.

63. Anderson J, Al-Ali G, Wirth M, et al. Degarelix versus Goserelin (+Antiandrogen Flare Protection) in the Relief of Lower Urinary Tract Symptoms Secondary to Prostate Cancer: Results from a Phase IIIb Study (NCT00831233). Urol Int. Epub December 15, 2012.
64. Radu A, Pichon C, Camparo P, et al. Expression of folliclestimulating hormone receptor in tumor blood vessels. $N$ Engl J Med. 2010;363(17):1621-1630.

65. Ben-Josef E, Yang SY, Ji TH, et al. Hormone-refractory prostate cancer cells express functional follicle-stimulating hormone receptor (FSHR). J Urol. 1999;161(3):970-976.

66. Ulmert D, Vickers AJ, Scher HI, et al. Rapid elimination kinetics of free PSA or human kallikrein-related peptidase 2 after initiation of gonadotropin-releasing hormone-antagonist treatment of prostate cancer: potential for rapid monitoring of treatment responses. Clin Chem Lab Med. 2012;50(11):1993-1998.

\section{Publish your work in this journal}

OncoTargets and Therapy is an international, peer-reviewed, open access journal focusing on the pathological basis of all cancers, potential targets for therapy and treatment protocols employed to improve the management of cancer patients. The journal also focuses on the impact of management programs and new therapeutic agents and protocols on

\section{Dovepress}

patient perspectives such as quality of life, adherence and satisfaction. The manuscript management system is completely online and includes a very quick and fair peer-review system, which is all easy to use. Visit http://www.dovepress.com/testimonials.php to read real quotes from published authors. 